thirteen tubers planted May 4, nine furnished plants, which bloomed July 12, and in September ripened a crop of tubers no larger than the seed planted, or of the size of small hazel-nuts. The leaves were small, deep grayish-green above, not hairy; the stems, much branched, deep purple at the nodes; the flowers, white and numerous. The tubers were veny diffusely spread in the soil.

An analysis of the tubers harvested by the station chemist, Dr. S. M. Babcock, is as below: -

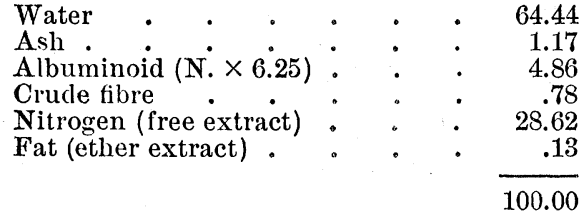

E. Lewis Sturtevant, Director.

N. Y. agricultural experiment-station, Geneva, N.Y., Nov. 14, 1883.

\section{Musical sand.}

In September (no. 31) you published a brief abstract of our preliminary paper on the singing-beach of Manchester, Mass. Since then we have continued our investigations, and collected additionål data and material. One of us has just returned from a visit to the singing-beach on the west shore of Lake Champlain, four miles and a half south of Plattsburg, Clinton county, N.Y. 'This beach is about seven hundred feet long, crescent-shaped, and terminates at the south end in low cliffs of limestone, and at the north end in shelving rocks of the same material. About a hundred feet north of the beach the limestone is quarried for building-purposes.

The acoustic phenomena previously described in connection with Manchester and Eigg are reproduced at Lake Champlain quite perfectly. On the occasion of our visit, however, the sand retained traces of moisture, and the noise, indicated by the syllable groosh, was less strong than it would otherwise have been. Two tests, however, showed that the sound made by rubbing the sand with the hand, and pressing it on the strata below, could be heard distinctly at a distance of more than a hundred feet. The tingling sensation in the toes, produced by striking the sand with the feet, was also perceived. We failed, however, to obtain sounds by rubbing the sand between the palms of the hands, - a method which yielded remarkable results at Manchester and at Eigg; but this failure is doubtless due to the imperfect dryness of the sand. Having learned, by experience with samples from the aforesaid localities, that they lose their acoustic properties after repeated friction, we tested this question directly on the beach. We found, that, by rubbing a definite quantity of sand continuously, its power of emitting sounds gradually diminished, and finally ceased.

The sand is unusually fine, and its grains of remarkably uniform size, averaging about 0.2 millimetre in diameter. Even to the naked eye their tendency to a spherical shape is apparent; and, when examined under the microscope, they are found to consist, to the amount of about thirty per cent, of round and polished grains of colorless quartz, usually of spherical, ellipsoidal, and reniform shapes; about the same quantity of angular to subangular grains of the same mineral, colorless, reddish, and yellowish, sometimes enclosing scales of hematite, grains of magnetite, and fluid cavities; a considerable number of fragments of a triclinic felspar, angular to subangular, colorless, and sometimes exhibiting cleavage-planes, and lines of striation; many short fibres and fragments of hornblende, and apparently augite, of a deep green color, often irregularly colored reddish brown by decomposition, and possessing strong dichroism; and a few minute particles of menaccanite and magnetite.

In conclusion, we will be greatly obliged to any reader of SCIENCE for information of additional localities of sonorous sand, and especially for samples for microscopical study.

Nov. $19,1883$.

H. C. Bolton and A. A. Junten.

\section{November shower of meteors.}

Watch was kept here for the November shower of meteors by myself and a number of students on the mornings of the $13 \mathrm{th}$ and $14 \mathrm{th},-$ on the $13 \mathrm{th}$ from 2 to 4 , on the 14 th from 2 to 6 . The observers were in a room having southern and eastern exposures, and meteoroids were looked for only in those directions. It was quite cloudy on the 13th, and only one meteoroid was seen; nearly clear on the 14th; and considering the fact that the moon was nearly full, and stars of the fourth magnitude could not be seen without attention, more meteoroids were seen than were expected, nearly all coming from the radiant in Leo. Owing to the fact that their appearance was not frequent enough to maintain constant attention, it is likely that most of those which were near the limits of visibility escaped observation. The maximum seemed to be at about 4.30 . At 3.20 a very brilliant one, much exceeding Sirius in brilliancy, was seen. Michigan agricultural college. $\quad$ L. G. CARPENTER.

\section{SOME RECENT STUDIES ON IDEAS OF MOTION.}

Studien über die bewegungs vorstellungen. Von Dr. S. Stricker, professor in Wien. Wien, Braumiller, $1882 . \quad 6+72$ p. $8^{\circ}$.

These studies are efforts in experimental psychology, with accompanying speculations, by a physiologist who has already written upon like subjects in his 'Studien über das bewusstsein.' 'The style is fragmentary, and not always very clear ; and there are some confusing efforts to frame a new terminology. Above all, the author's training in general philosophy is very imperfect; and therefore what he says in the latter half of this essay, "Ueber die quellen unserer vorstellungen von der causalität,' is almost wholly antiquated and insignificant, having been superseded ever since Hume, whom, in fact, our author seems in one respect to have wholly misapprehended. But in his direct observations of mental facts, Professor Stricker attracts one's attention as having given some independent contribution to the discussions about the relation of the muscular sense to our ideas of motion. Even here, it must be remarked, he pays little attention to the fact that others have been at work before him, and seems to think his ideas quite new. Yet what he has done is to observe, and record his observations; and in so far forth he has done what we want done in the psychological field. 